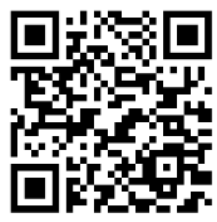

Journal An-Nafs: Kajian Penelitian Psikologi https://ejournal.iai-tribakti.ac.id/index.php/psikologi e-ISSN: 2549-6166 p-ISSN: 2528-0600 DOI: $10.33367 /$ psi.v5i1.1081

Submitted: 2020-02-27

Revised : 2020-03-28

Accepted : 2020-04-16

Published: 2020-06-01

\title{
GEGAR BUDAYA DITINJAU DARI DUKUNGAN SOSIAL PADA MAHASISWA THAILAND SELATAN (PATANI)
}

\author{
Irfani Rizal ${ }^{1}$, Icha Herawati ${ }^{2}$ \\ 1irfanirizal27@psy.uir.ac.id, 2 ichaherawati@psy.uir.ac.id
}

Universitas Islam Riau

\begin{abstract}
Cultural differences experienced by Thailand Selatan (Patani) students with Indonesian culture can cause cultural shock to Patani students. Culture shock is a reaction of individual discomfort when entering a new environment. One of the strategies in reducing culture shock is to get social support. This research examines whether there is a correlation between social support and culture shock in Patani students at the Islamic University of Riau. The research method used is quantitative research. Data collection was carried out using a scale of culture shock and social support scale. Pearson product-moment analysis was used to test the proposed hypothesis. Participants numbered 52 people using saturated sample techniques. The results showed that a negative and significant relationship between social support and culture shock in Patani students at the Islamic University of Riau with the $r=-0,276$ with $p$ $0,024(p<0,05)$. The conclusion from this study shows that the higher the social support, the lower the culture shock. The culture shock was predicted by social support of 7.6\%.
\end{abstract}

Keyword: Culture shock, Social support, Patani students

\begin{abstract}
Abstrak
Perbedaan budaya yang dirasakan oleh mahasiswa Thailand Selatan (Patani) dengan budaya Indonesia dapat menimbulkan gegar budaya. Gegar budaya merupakan suatu reaksi ketidaknyamanan individu ketika memasuki lingkungan baru. Salah satu strategi dalam mengurangi gegar budaya adalah dengan mendapatkan dukungan sosial. Penelitian ini menguji apakah ada hubungan antara dukungan sosial dengan gegar budaya pada mahasiswa Patani di Universitas Islam Riau. Metode penelitian yang digunakan adalah metode penelitian kuantitatif. Pengumpulan data dilakukan menggunakan skala yaitu skala gegar budaya dan skala dukungan sosial. Analisis Pearson product moment digunakan untuk menguji hipotesis pada penelitian ini. Partisipan penelitian berjumlah 52 orang dengan menggunakan teknik sampel jenuh. Hasil penelitian menunjukkan bahwa hubungan yang negatif dan signifikan antara dukungan sosial dengan gegar budaya pada mahasiswa Patani di Universitas Islam Riau dengan $r=-0,276$ dengan $p 0,024(p<0,05)$. Kesimpulan dari penelitian ini menunjukkan bahwa semakin tinggi dukungan sosial maka semakin rendah gegar budaya. Gegar budaya diprediksi oleh dukungan sosial sebesar $7,6 \%$.
\end{abstract}

Kata Kunci: Gegar Budaya, Dukungan Sosial, Mahasiswa Patani 
Irfani Rizal \& Icha Herawati | Gegar Budaya Ditinjau dari Dukungan Sosial

\section{PENDAHULUAN}

Universitas Islam Riau merupakan salah satu universitas swasta tertua di Provinsi Riau yang mana universitas ini sedang berkembang dengan pesat. Visi dari Universitas Islam Riau adalah menjadikan Universitas Islam Riau unggul dan terkemuka di Asia Tenggara pada tahun 2020. Universitas Islam Riau merupakan salah satu universitas di Riau yang menerima kerjasama dengan luar negeri dan menerima mahasiswa asing yang ingin melanjutkan perkuliahan. Berdasarkan data dari Internatinal Office Universitas Islam Riau terdapat 110 mahasiswa yang berasal dari berbagai negara tetangga seperti, Malaysia, Timor Leste, Mesir, dan Thailand Selatan yaitu Pattani. Mahasiswa dari Pattani merupakan mahasiswa asing dengan jumlah terbanyak di UIR. Tahun 2019 mahasiwa Thailand yang aktif berjumlah 61 orang terbagi dengan beberapa fakultas dan mayoritas mengambil jurusan Pendidikan Agama Islam (Maulizon, 2019) mahasiswa asal Patani merupakan kelompok minoritas muslim di Thailand Selatan, mayoritas agama di Thailand adalah Budha (Phillips, 2007). Mahasiswa Patani yang menempuh pendidikan di Universitas Islam Riau akan tinggal dan menetap lebih lama dilingkungan yang baru dan berbeda dari daerah asalnya.

Penelitian ini berangkat dari adanya perbedaan budaya antara negara asal para mahasiswa asing dengan Indonesia sehingga menimbulkan gegar budaya terhadap mahasiswa asing. Beberapa faktor yang mempengaruhi gegar budaya adalah manajemen stress yang buruk, kebingungan identitas, kurangnya dukungan sosial serta prasangka, terjadi perbedaan dalam bahasa, kesulitan dalam komunikasi serta lingkungan, pengalaman sebelumnya, trait personal, akses sumber daya, perbedaan etnis, jenis kelamin, perbedaan budaya yang meresahkan, mahasiswa asing kadang-kadang merasakan perasaan isolasi yang mendalam sehingga terjadi gegar budaya (Brislin \& Yoshida, 1994; Goldstein \& Keller, 2015). Faktor lainnya yang menyebabkan orang asing mengalami gegar budaya adalah karena "homesick" atau rindu terhadap rumah (Lai \& Wang, 2019)

Berdasarkan hasil wawancara dan observasi yang dilakukan, permasalahanpermasalahan yang lazim ditemui oleh mahasiswa Patani adalah kesulitan dalam berbahasa yang membuat mahasiswa Patani malu dan minder sehingga kesulitan dalam bersosialisasi dengan teman-teman yang berasal dari Indonesia dampaknya adalah mahasiswa Patani enggan untuk berkempul dengan orang Indonesia karena sulit untuk berkomunikasi dan pertemanan mereka hanya sesama mahasiswa yang berasal dari Patani, selanjutnya masalah cita rasa makanan, berdasarkan wawancara mahasiswa Patani terbiasa dengan masakan yang asin dan asam sedangkan di Indonesia sendiri 
sangat terkenal dengan masakan pedas, permasalahan lainnya yakni terkait perbedaan budaya, di Patani sangat tabu ketika seorang laki-laki dan perempuan jalan bersama, mereka memandang itu adalah hal yang tidak boleh dilakukan sedangkan di Indonesia sendiri itu merupakan hal yang biasa ketika seorang laki-laki dan perempuan jalan bersama-sama. Penelitian yang dilakukan oleh (Khoirunnisa \& Soemantri, 2019) menjelaskan bahwa jenis gegar budaya yang di alami pada warga Negara Perancis adalah pada kategori bahasa, kategori makanan, kategori cuaca/ musim dan kategori peraturan lalu lintas atau ketertiban.

Selain itu juga, dari cara berpakaian perempuan asal Patani terbiasa untuk memakai cadar dan jilbab syar'i serta juga terbiasa untuk menggunakan pakaian dengan warna yang gelap, sedangkan di Indonesia sendiri mahasiswa Patani sangat jarang melihat perempuan di Indonesia yang bercadar, meskipun beberapa mahasiswa asal Indonesia yang menjalankan perkuliahan di Universitas Islam Riau menggunakan cadar tetapi sangat jarang terlihat dan dari warna pakaian yang digunakan kebanyakan orang Indonesia menggunakan pakaian yang berwarna-warna cerah, hal ini merupakan ciri budaya dari mahasiswa Pattani. Beberapa permasalahan-permasalahan ini yang mengakibatkan mahasiswa Pattani mengalami "keterkejutan budaya" atau disebut juga dengan gegar budaya (culture shock).

Gegar budaya pertama kali diperkenalkan oleh Kalvero Oberg (1960) yang merupakan seorang antropoligis. Menurut (Oberg, 1960) gegar budaya menggambarkan keadaan psikologis yang negatif, individu bereaksi pasif ketika dihadapkan pada lingkungan budaya yang berbeda. Dalam hal ini, respon yang diberikan terhadap lingkungan budaya yang berbeda tersebut merupakan suatu proses yang berlangsung terus-menerus selalu berhubungan dengan perubahan budaya yang terjadi. Gegar budaya merupakan sebuah reaksi psikologis maladaptif dan gangguan mental yang terjadi sebagai respons terhadap transisi dari satu latar budaya ke lingkungan lainnya yang berkelanjutan dari proses akulturasi (Berman, Audrey.; Kozier, Barbara.; Erb, 2012). Furnham (2019) mendefiniskan bahwa gegar budaya adalah suatu reaksi individu terhadap lingkungan, pengalaman, dan orang baru yang akan mengejutkan, membuat stres, dan membutuhkan kemampuan untuk dapat menyesuaikan diri dengan orang baru.

Salah satu cara atau strategi dalam mengurangi gegar budaya adalah dengan adanya dukungan sosial. Dukungan sosial yang dimaksud dalam bentuk diskusi dan komunikasi merupakan salah satu cara untuk menemukan dukungan sosial, diskusi dengan lingkungan terdekat serta melakukan komunikasi dengan masyarakat asal (Wahyuni, 2019). Penelitian yang dilakukan oleh (Xia, 2009) memaparkan bahwa untuk 
mendapatkan dukungan sosial, seseorang akan menerima hiburan, kepedulian, dorongan, nasehat dan bantuan dari orang-orang dilingkungan sekitar. Ketika individu mendapatkan dukungan dengan orang lingkungan barunya maka akan mengurangi gegar budaya yang mahasiswa asing alami. Dukungan sosial yang diterima membuat individu merasa tenang, diperhatikan, dicintai, timbulrasa percaya diri dan kompeten (Kumalasari \& Ahyani, 2012).

Gegar budaya pada mahasiswa asing menjadi penting untuk diteliti karena penelitian sebelumnya masih menggunakan subjek pada mahasiswa yang berasal dari Indonesia atau luar pulau saja (Oktaria \& Kustanti, 2018; Pramudiana \& Setyorini, 2019). Adapun penelitian mengenai penyebab gegar budaya yakni dukungan sosial sudah pernah dilakukan namun masih belum banyak sehingga dibutuhkan riset mengenai topik tersebut. Selain itu juga beberapa riset dilakukan pada budaya barat, masih sedikit penelitian yang dilakukan di Asia dan menyoroti pada mahasiswa asing. Diharapkan hasil dari penelitian ini dapat memperkaya riset yang mewakili dari negara Asia. Peneliti tertarik untuk melakukan penelitian, dikarenakan gegar budaya yang dirasakan mahasiswa Patani dapat dipengaruhi oleh dukungan sosial dari orang lain misalnya saja nasehat, diskusi, komunikasi serta saran. Hipotesis dalam penelitian ini adalah ada hubungan antara dukungan sosial dengan gegar budaya pada mahasiswa Patani di Universitas Islam Riau.

\section{METODE}

Penelitian ini merupakan penelitian kuantitatif. Peneliti mengambil sampel sebanyak 52 orang dengan menggunakan metode sampling jenuh. Sampling jenuh merupakan teknik penentuan sampel bila semua anggota populasi digunakan sebagai sampel. Maka dari itu, penulis memilih sampel menggunakan teknik sampling jenuh karena jumlah populasi yang relatif kecil. Sehingga sampel yang digunakan pada penelitian ini berjumlah 52 orang. Penulis menggunakan sampling jenuh dikarenakan jumlah populasi mahasiswa Pattani yang melanjutkan perkuliahan di Universitas Islam Riau berjumlah 61 orang.

Alat ukur yang digunakan dalam penelitian ini adalah skala gegar budaya yang di adaptasi oleh Maulizon O.J (2019) terdiri dari 46 aitem, sedangkan pada skala dukungan sosial disusun berdasarkan empat aspek dukungan sosial menurut House (dalam Smet, 1994) yaitu dukungan emosional, dukungan penghargaan, dukungan instrumental dan dukungan informasi. Alat ukur ini menggunakan model skala Likert yang memiliki empat alternative jawaban, yaitu Sangat Setuju (SS), Setuju (S), Tidak Setuju (TS) dan Sangat 
Tidak Setuju (STS). Data dianalisis menggunakan uji korelasi yaitu pearson product moment untuk menguji hipotesis dalam penelitian ini. Sebelum melakukan uji hipotesis, penulis terlebih dahulu melakukan uji asumsi dasar yaitu uji normalitas dan uji linearitas.

\section{PAPARAN HASIL}

Penelitian ini untuk menguji apakah ada hubungan antara dukungan sosial dengan gegar budaya pada mahasiswa Patani, sebelum melakukan uji hipotesis terlebih dahulu peneliti melakukan uji validitas, uji reliabilitas dan uji asumsi dasar.

Tabel 1. Blueprint Skala Gegar Budaya

\begin{tabular}{ccccc}
\hline \multirow{2}{*}{ No } & \multirow{2}{*}{ Aspek } & \multicolumn{2}{c}{ Aitem } & \multirow{2}{*}{ Jumlah } \\
\cline { 2 - 5 } & Affective & $1,2,3,4,15,16,17,18,19,20,21,22$ & $13,24,25,27,36,43$ & 18 \\
\hline 2 & Behavior & $5,10,14,31,32,33,34,35$ & $6,8,12,28,30,37,44$ & 15 \\
\hline 3 & Cognitive & $11,38,39,40,41,42,45,46$ & $7,9,23,26,29$ & 13 \\
\hline \multicolumn{4}{c}{ Jumlah } & 46 \\
\hline
\end{tabular}

Tabel 2. Blueprint Skala Dukungan Sosial

\begin{tabular}{|c|c|c|c|c|}
\hline \multirow{2}{*}{ No } & \multirow{2}{*}{ Aspek } & \multicolumn{2}{|c|}{ Aitem } & \multirow{2}{*}{ Jumlah } \\
\hline & & Favorable & Unfavorable & \\
\hline 1 & Dukungan Penghargaan & $1,5,17,22$ & $9,13,18$ & 7 \\
\hline 2 & Dukungan Penghargaan & $2,6,19$ & 10,14 & 5 \\
\hline 3 & Dukungan Instrumental & $3,7,21$ & $11,15,20$ & 6 \\
\hline 4 & Dukungan Informatif & $4,8,23,24$ & 12,16 & 6 \\
\hline & \multicolumn{3}{|c|}{ Jumlah } & 24 \\
\hline
\end{tabular}

Berdasarkan tabel 1 dan 2 menjelaskan blue print dari skala gegar budaya dan dukungan sosial. Jumlah aitem penelitian pada skala gegar budaya berjumlah 46 aitem, sedangkan pada variabel dukungan sosial berjumlah 24 aitem.

Tabel 3. Hasil Uji Validitas

\begin{tabular}{lcc}
\hline & Variabel & Indeks Validitas \\
\hline Gegar Budaya & $0,285-0,686$ \\
\hline Dukungan Sosial & $0,286-0,694$ \\
\hline
\end{tabular}

Berdasarkan tabel 3. Maka dapat dinyatakan bahwa skala yang digunakan valid dengan rentang nilai validitas pada variabel gegar budaya 0,285 sampai dengan 0,686 dan variabel dukungan sosial berkisar antara 0,286 sampai dengan 0,694.

Tabel 4. Hasil Uji Reliabilitas

\begin{tabular}{lll}
\hline & Variabel & Alpha \\
\hline Gegar Budaya & 0,896 \\
\hline Dukungan Sosial & 0,870 \\
\hline
\end{tabular}


Irfani Rizal \& Icha Herawati | Gegar Budaya Ditinjau dari Dukungan Sosial

Berdasarkan tabel 4, konsistensi cronbach alpha digunakan untuk menguji reliabilitas alat ukur. Reliabilitas pada skala gegar budaya sebesar 0,896, sedangkan pada variabel dukungan sosial sebesar 0,870. Maka dapat disimpulkan bahwa data penelitian reliabel karena reliabilitas pada setiap instrument > 0,60 (Cronbach Alpha).

Tabel 5. Hasil Uji Normalitas One Sample Kolmogorov-Smirnov Test

\begin{tabular}{cccc}
\hline Variabel & KS & $P$ & Keterangan \\
\hline Gegar budaya & 0,729 & 0,662 & Normal \\
\hline Dukungan sosial & 0,890 & 0,407 & Normal \\
\hline
\end{tabular}

Berdasarkan tabel 5 menunjukkan hasil dari uji normalitas pada variabel gegar budaya melalui uji normalitas ditemukan bahwa nilai KS sebesar 0,729 dengan nilai signifikansi $(p)=0,662(p>0,05)$, sedangkan pada variabel dukungan sosial memperoleh hasil KS dengan nilai 0,890 dan taraf signifikansi $(p)=0,407(p>0,05)$. Maka dapat disimpulkan bahwa data berdistribusi normal.

Tabel 6. Hasil Uji Linearitas

\begin{tabular}{lccc}
\hline \multirow{2}{*}{ Variabel } & \multicolumn{2}{c}{ Deviation from Linearity } & Keterangan \\
\cline { 2 - 4 } & $\mathrm{f}$ & $\mathrm{p}$ & \\
\hline${ }^{*}$ DukunganSosial & 1.409 & 0.193 & Linear \\
\hline
\end{tabular}

Berdasarkan tabel 6, menunjukkan uji linearitas yang dilakukan antara gegar budaya dan diketahui nilai $\mathrm{F}$ (deviation from linierity) sebesar 1,409 dengan nilai signifikasinya $(p)=0,193(p>0,05)$. Berdasarkan hasil tersebut dapat disimpulkan bahwa ada hubungan yang linear antara dukungan sosial dengan gegar budaya pada mahasiswa Patani.

Tabel 7. Hasil Analis Uji Korelasi

\begin{tabular}{ccccc}
\hline Variabel & Mean & SD & 1 & 2 \\
\hline Gegar Budaya & 106,00 & 7,934 & 1 & $-0,276$ \\
\hline Dukungan Sosial & 74,12 & 7,202 & $-0,276$ & 1 \\
\hline $\mathrm{p}=0,024(\mathrm{p}<0,05)$ & & & &
\end{tabular}

Setelah melakukan uji hipotesis melalui uji Pearson product moment, menunjukkan bahwa ada hubungan negatif dan siginifikan antara dukungan sosial terhadap gegar budaya dengan nilai $r=-0,276$ dengan p 0,024 $(\mathrm{p}<0,05)$. Maka dapat disimpulkan bahwa semakin tinggi dukungan sosial maka semakin rendah gegar budaya. Begitupun sebaliknya, semakin rendah dukungan sosial maka semakin tinggi gegar budaya.

Tabel 8. Hasil Uji Analisis Koefisian Determinasi

\begin{tabular}{cccc}
\hline $\mathrm{R}$ & $\mathrm{R}$ Square & Adjusted R Square & $\begin{array}{c}\text { Std. Error of the } \\
\text { Estimate }\end{array}$ \\
\hline 0,276 & 0,076 & 0,058 & 7.701 \\
\hline
\end{tabular}


Irfani Rizal \& Icha Herawati | Gegar Budaya Ditinjau dari Dukungan Sosial

Tabel 8 menunjukkan bahwa nilai $\mathrm{R}^{2}$ sebesar 0,076, nilai ini menunjukkan sumbangan dukungan sosial terhadap gegar budaya. Berdasarkan nilai tersebut, maka dapat diartikan bahwa sumbangan efektif yang diberikan oleh dukungan sosial dalam menekan terjadinya gegar budaya sebesar 7,6 \% dan sisanya 92,4\% dipengaruhi oleh variabel lainnya yang tidak termasuk dalam penelitian ini.

Tabel 9. Data Demografi

\begin{tabular}{ccc}
\hline Jenis kelamin & Frekuensi & Persen \\
\hline Laki-laki & 31 & $59,61 \%$ \\
\hline Perempuan & 21 & $40,38 \%$ \\
\hline Usia & & \\
\hline 19 & 2 & $3,84 \%$ \\
\hline 20 & 1 & $1,92 \%$ \\
\hline 21 & 3 & $5,76 \%$ \\
\hline 22 & 7 & $13,46 \%$ \\
\hline 23 & 13 & $25 \%$ \\
\hline 24 & 4 & $7,69 \%$ \\
\hline 25 & 10 & $19,23 \%$ \\
\hline 26 & 7 & 13,46 \\
\hline 27 & 1 & $1,92 \%$ \\
\hline 29 & 3 & $5,76 \%$ \\
\hline 3 & 1 & $1,92 \%$
\end{tabular}

\begin{tabular}{cccc}
\hline Semester & & \\
\hline 1 & 4 & $7,69 \%$ \\
\hline 3 & 4 & $7,69 \%$ \\
\hline 5 & 7 & $13,46 \%$ \\
\hline 7 & 17 & $32,69 \%$ \\
\hline 9 & 16 & $30,76 \%$ \\
11 & 4 & $7,69 \%$ \\
\hline
\end{tabular}

Tabel 9 menunjukkan data demografi dari mahasiswa Patani, dengan jumlah lakilaki sebanyak 31 orang atau sebesar 59,61 persen dan perempuan sebanyak 21 orang atau sebesar sebesar 40,38 persen. Selanjutnya dari kategori usia, terlihat bahwa jumlah mahasiswa Patani terbanyak pada usia 23 tahun sebanyak 13 orang atau sebesar 25\% persen. Selanjutnya, berdasarkan pada kategori semester, maka dapat disimpulkan bahwa pada mahaaisswa Patani mayoritas berada pada semester 7 berjumlah 17 orang atau 32,69 persen,

\section{PEMBAHASAN}

Hasil deskriptif data penelitian yang telah dilakukan peneliti, berdasarkan data yang telah dipaparkan menunjukkan bahwa pada mahasiswa Patani mengalami gegar budaya yang tinggi serta mendapatkan dukungan sosial pada kategori sedang. Mahasiswa Patani masih mengalami gegar budaya yang tinggi hal ini dikarenakan mahasiswa Patani 
belum secara penuh mendapatkan dukungan sosial dari lingkungan baik itu dari teman sebaya maupun keluarga.

Hasil dari penelitian ini sejalan dengan penelitian terdahulu yang menyatakan bahwa dukungan sosial merupakan faktor yang sangat penting terkait dengan tingkat gegar budaya. Kualitas dukungan yang diterima diakui sebagai aspek dukungan sosial yang paling erat kaitannya dengan gangguan psikologis yang dialami oleh siswa internasional. Selanjutnya, hal ini juga sejalan dengan penelitian yang dilakukan oleh (Thomas \& Sumathi, 2016) yang mengatakan bahwa dukungan sosial ditemukan sangat penting bagi siswa internasional karena mereka jauh dari keluarga mereka dan mereka sering merasa kesepian dan mereka memiliki kerinduan dan beberapa didiskriminasi yang diterima oleh siswa internasional. Dukungan sosial dapat membantu mereka mengurangi gegar budaya yang mereka hadapi. Terutama dukungan sosial dari keluarga memiliki hubungan yang kuat dengan tekanan budaya baru yang dihadapinya, dukungan yang diberikan oleh keluarga dapat mengurangi gegar budaya yang dihadapi mahasiswa.

LittleJohn (2004) menjelaskan bahwa gegar budaya yang dirasakan pada mahasiswa perantau merupakan hal yang wajar ketika berkunjung pada budaya yang baru. Budaya diekspresikan sebagai kejutan yang tidak menyenangkan atau kejutan yang dihadapkan dengan hal aneh yang tidak dikenal atau tidak biasa. Gegar budaya biasanya terjadi dalam jangka pendek karena mengalami keterkejutan dengan budaya baru. Terjadinya gegar budaya ketika berurusan dengan lingkungan budaya baru, merespons stimulus asing, menemukan berbagai cara dalam melakukan sesuatu, mengajukan pertanyaan, mengenal jawaban atau bahkan belajar tentang makanan. Individu yang mengunjungi budaya asing terkejut ketika mereka tidak menyadari perbedaan dalam budaya asing yang dikunjungi, bagaimana harus berperilaku dalam budaya baru, dan ketika mengalami sikap negatif seperti kehilangan keakraban, kehilangan simbol hubungan sosial atau kehilangan keseimbangan karena kesulitan beradaptasi dengan lingkungan baru (Rusev dkk., 2018).Gegar budaya merupakan salah satu reaksi yang umumnya dirasakan oleh individu yang merantau disebabkan karena merasa kaget atas perbedaan-perbedaan yang dirasakan seperti budaya, bahasa, makanan, kehidupan sosial, cuaca dan sebagainya. Secara tidak langsung mahasiswa asing dituntut untuk melakukan penyesuaian terhadap hal yang baru yang ada di sekitar lingkungannya.

Beberapa fase yang dialami individu ketika mengalami gegar budaya adalah yang pertama berada pada fase "honeymoon" yakni perasaan senang, euphoria, senang, kagum dan antusias. Fase berikutnya yaitu fase frustration, fase ini adalah mahasiswa bersemangat dan penasaran yang berubah menjadi frustrasi, jengkel serta merasa tidak 
mampu berbuat apa-apa karena lingkungan baru tidak sesuai dengan ekspektasi yang ada. Pada mahasiswa yang mengalami gegar budaya berada pada fase crisis yang ditunjukkan dengan perasaan-perasaan frustrasi, cemas, serta kemarahan. Selanjutnya fase penyesuaian diri (fase readjustment) mahasiswa asing melakukan penyesuaian kembali dan mulai mengembangkan berbagai cara untuk bisa beradaptasi dengan lingkungan baru misalnya dengan mempelajari bahasa, cita rasa makanan dan budaya setempat. Terakhir pada fase resolution yaitu mahasiswa mencari jalan keluar dari ketidaknyamanan yang dirasakan oleh mahasiswa (Indrianie, 2012))

Berdasarkan hasil yang telah diperoleh, maka hal ini sejalan dengan penelitian yang dilakukan oleh (Sullivan \& Kashubeck-West, 2015) menjelaskan bahwa dukungan sosial dapat membantu mahasiswa asing yang mengalami gegar budaya agar mampu menyesuaikan diri dengan lingkungan dan budaya setempat, misalnya dengan mengembangkan koneksi ke kampus dan komunitas lokal, selain itu mendorong mahasiswa asing untuk mengikuti perkembangan sosial yang lebih luas, melibatkan atau membantu mahasiswa asing dalam meningkatkan keterampilan sosial, serta mengajak dan memberi informasi mahasiswa asing untuk mengikuti organisasi dan kegiatan di kampus sehingga dapat memnambah pertemanan.

Beberapa hal yang dapat dilakukan untuk mengatasi gegar budaya misalnya dengan melakukan pelatihan penyesuaian budaya (Indrianie, 2012), selain itu juga dukungan sosial merupakan cara yang dapat dilakukan dalam mengatasi gegar budaya pada mahasiswa asing. Dukungan sosial baik itu dari keluarga maupun teman sebaya, akan membawa efek positif yaitu sebagai pelepasan emosi dalam mengurangi kecemasan sehingga individu tersebut merasa diterima oleh lingkungan sekitarnya hal ini membuat mahasiswa asing dapat mengatasi gegar budaya yang dirasakannya. Smet (1994) mengemukakan bahwa dukungan sosial adalah dukungan yang didapat dari keakraban sosial (teman, keluarga, anak ataupun orang lain) berupa pemberian informasi, nasehat verbal atau non verbal, bantuan nyata atau tidak nyata, tindakan yang bermanfaat sosial dan efek perilaku bagi penerima yang akan melindungi diri dari perilaku yang negatif.

Beberapa peneliti mengklaim bahwa dukungan sosial merupakan kontributor yang signifikan untuk mengatasi tantangan yang dialami mahasiswa internasional selama adaptasi sekolah. Mahasiswa asing sangat bergantung pada dukungan sosial dari temanteman yang mereka temui di U.S (Lee dkk., 2018). Winkelman (1994) berpendapat bahwa dukungan sosial membantu untuk memperbaiki stresor, mengurangi kejutan budaya, dan memfasilitasi penyesuaian antar budaya. Salah satu caranya adalah dengan mengikuti organisasi. Banyak mahasiswa asing mulai mencari teman sebaya yang memiliki latar 
belakang etnis dan budaya yang sama untuk membangun atau menjadi anggota komunitas etnis. Mahasiswa asing merasa nyaman dan lebih mudah untuk menjalin pertemanan dengan orang-orang yang memiliki latar budaya yang sama dari negara yang sama, tetapi penting juga untuk mengembangkan sosialisasi dengan kelompok mahasiswa yang lebih beragam (Sullivan \& Kashubeck-West, 2015).

Dukungan dari keluarga dan teman-teman dapat mengurangi stres dan ini akan berdampak positif pada mahasiswa dan mereka akan dapat menyesuaikan diri dengan lingkungan baru, gender juga memainkan peran dalam stres. Dukungan sosial yang kuat akan mengurangi stres yang dihadapi mahasiswa. Amponsah (2010) menyatakan bahwa strategi penanggulangan stres yang paling sering digunakan oleh siswa internasional adalah penanggulangan stres yang berorientasi masalah, yang kedua adalah mencari dukungan sosial dan yang ketiga adalah strategi peniadaan perilaku.

\section{SIMPULAN}

Berdasarkan penelitian yang telah dilakukan maka dapat disimpulkan bahwa ada hubungan negatif yang signifikan antara dukungan sosial dengan gegar budaya pada mahasiswa Patani di Universitas Islam Riau, semakin tinggi dukungan sosial yang diperoleh mahasiswa Patani maka semakin rendah gegar budaya yang dialami mahasiswa Patani tersebut. Dukungan sosial dapat menekan gegar budaya dengan nilai sumbangan efektif sebesar 7,6\%.

Bagi pihak-pihak yang berminat dengan penelitian tentang gegar budaya atau ingin mengembangkan penelitian lebih jauh, maka penulis memberikan saran 1) Melakukan penelitian secara mendalam mengenai faktor-faktor lainnya yang menjadi penyebab gegar budaya pada mahasiswa asing dan melakukan penelitian untuk mengurangi gegar budaya; 2) Melakukan penelitian lebih mendalam tentang gegar budaya dalam hubungannya dengan variabel lain yang tidak diteliti dalam penelitian ini misalnya dari variabel kepribadian, penyesuaian diri atau adaptasi; 3) Bagi pihak Universitas Islam Riau hendaknya mengadakan kelas bahasa terkait dengan pembelajaran bahasa Indonesia sebelum memasuki perkuliahan di Universitas Islam Riau, 4) Bagi mahasiswa Patani diharapkan untuk dapat beradaptasi dengan baik dan tidak malu untuk menjalin pertemanan dengan mahasiswa yang berasal dari Pekanbaru serta tidak malu untuk bertanya dan memulai berbicara dengan mahasiswa lainnya 
Irfani Rizal \& Icha Herawati | Gegar Budaya Ditinjau dari Dukungan Sosial

\section{DAFTAR PUSTAKA}

Amponsah, M. (2010). Non UK University students stress levels and their coping Strategies. Educational Research, 1, 88-98.

Berman, Audrey.; Kozier, Barbara.; Erb, G. L. (2012). Fundamentals of Nursing VOLUME ONE.

Brislin, R., \& Yoshida, T. (1994). Intercultural Communication Training: An Introduction. SAGE Publications, Inc. https://doi.org/10.4135/9781452243603

Furnham, A. (2019). Culture Shock: A Review of the Literature for Practitioners. Psychology, 10(13), 1832-1855. https://doi.org/10.4236/psych.2019.1013119

Goldstein, S. B., \& Keller, S. R. (2015). U.S. college students' lay theories of culture shock. International Journal of Intercultural Relations, 47, 187-194. https://doi.org/10.1016/j.ijintrel.2015.05.010

Indrianie, E. (2012). Culture Adjustment Training untuk Mengatasi Culture Shock pada Mahasiswa Baru yang Berasal dari Luar Jawa Barat. Insan, 14(65), 149-158.

Khoirunnisa, Y., \& Soemantri, N. P. (2019). Fenomena Gegar Budaya Pada Warga Negara Perancis yang Bekerja di Jakarta. Jurnal Antropologi: Isu-isu Sosial Budaya, 21(02), 254-261.

Kumalasari, F., \& Ahyani, L. N. (2012). Hubungan Antara Dukungan Sosial Dengan Penyesuaian Diri Remaja Di Panti Asuhan. Jurnal Psikologi: PITUTUR, 1(1), 19-28.

Lai, H., \& Wang, D. (2019). Factors Predicting the Culture Shock of Peace Corps Volunteers in the Western China Universities. International Journal of Social Sciences Perspectives, 5(2), 36-46. https://doi.org/10.33094/7.2017.2019.52.36.46

Lee, C., Sung, Y.-T., Zhou, Y., \& Lee, S. (2018). The relationships between the seriousness of leisure activities, social support and school adaptation among Asian international students in the U.S. Leisure Studies, 37(2), 197-210. https://doi.org/10.1080/02614367.2017.1339289

Littlejohn, S. (2004). Culture shock management: When you move to a new place, you are likely to experience a certain degree of culture shock. Though it can be very difficult for some, it is a worthwhile experience. Swiss News. https://www.thefreelibrary.com/Culture shock management: when you move to a new place, you are...-a0119267612

Maulizon, O. J. (2019). Hubungan Antara Keterampilan Sosial dengan Gegar Budaya Pada Mahasiswa Asing yang berada di Universitas Islam Riau.

Oberg, K. (1960). Cultural Shock: Adjustment to New Cultural Environments. Dalam Practical Anthropology (hlm. 177-182). https://doi.org/10.1177/009182966000700405

Oktaria, A. A. S., \& Kustanti, E. R. (2018). Hubungan Antara Gegar Budaya Dengan Penyesuaian Diri Pada Mahasiswa Bersuku Minang Di Universitas Diponegoro. Empati, 7(2), 48-65. 
Irfani Rizal \& Icha Herawati | Gegar Budaya Ditinjau dari Dukungan Sosial

Pramudiana, I. D., \& Setyorini, T. D. (2019). Hubungan Antara Gegar Budaya Dengan Penyesuaian Sosial Siswa Papua di Magelang. Praxis, 1(2), 125. https://doi.org/10.24167/praxis.v1i2.1631

Rusev, M., Strauss, E., Avcikurt, C., Soykan, A., Parlak, B., \& Efe, R. (2018). Social Sciences Researches in the Globalizing World. ST. Kliment Ohridski University Press.

Smet, B. (1994). Psikologi kesehatan. Grasindo. /freecontents/index.php/buku/detail/psikologi-kesehatan-bart-smet-26404.html

Sullivan, C., \& Kashubeck-West, S. (2015). The interplay of international students' acculturative stress, social support, and acculturation modes. Journal of International Students, 5(1), 1-11.

Thomas, F., \& Sumathi, G. N. (2016). Acculturative Stress and Social Support among the International Students: An Empirical Approach. Global Management Review, 10(3), $61-72$.

Wahyuni, D. S. (2019). Culture Shock Experiences of Indonesian University Students in Teaching Practice and Community Service in Thailand. Abjadia, 4(2), 78-96. https://doi.org/10.18860/abj.v4i2.6289

Winkelman, M. (1994). Cultural Shock and Adaptation. Journal of Counseling \& Development, 73(2), 121-126. https://doi.org/10.1002/j.15566676.1994.tb01723.x

Xia, J. (2009). Analysis of Impact of Culture Shock on Individual Psychology. International Journal of Psychological Studies, 1(2), 97-101. https://doi.org/10.5539/ijps.v1n2p97 